\title{
Changing reading paths in a digital age: What are the consequences for meaning-making?
}

\section{Zuzana Petrová, Rastislav Nemec}

Abstract: Everyday experience and a growing part of empirical research illustrate the changing reality of reading in our society in recent years. There are many empirical, pedagogical and philosophical studies that reflect on the falling level of general knowledge of the population and the superficiality of young people's reading comprehension. In this study, we aim to identify and analyse how reading is changing with the emergence of a new text architecture and the replacement of alphabetic, print-based text with screen-based text, and ask whether this new ontological variant could also bring about a change in the epistemological "qualities" of reading. We go beyond the design of digital text itself to ask how changes in text design affect the role of alphabetic text in meaning-making. We then examine specific aspects of the change in the nature of reading itself and how they could lead to a paradigmatic change in pedagogy and literacy.

Key words: meaning-making, alphabetic text, digital text elements, reading onscreen, reading printed text.

Technological progress is a topic that frequently attracts the attention of those making prognoses on the future development of the homo sapiens (Harari, 2016). Digital technologies and diverse educational reforms for the $21 \mathrm{st}$ century are the main symbol of such progress in education. The use of digital technologies, the digitization of learning resources and the implementation of e-learning platforms are intended to overcome the limits of traditional learning and promise to bring personalized benefits in the form of lifelong 
learning and contribute to learning that is open, appropriate, people-centred, equitable and sustainable (UNESCO, 2015). Behind this lies the ideal of a revolution in collective intelligence, potentially saturated with the availability of knowledge in a virtual, interconnected and ubiquitous space that enables the masses to benefit from reading and writing (Fišerová, 2015a). The normal, everyday reality will become one in which individuals are "creative conversation participants" able to "prioritize, select resources, filter information according to its quality, categorize and classify data, synthesize and relate information and discuss in a civilized way" (Fišerová, 2015a).

Many phenomena show that communication is increasingly being transferred to the online space, with individuals now spending a large amount of time using technologies. Bohn and Short (2009), in their report How Much Information? 2009 Report on American Consumers, state that US residents spent approximately 11.8 hours a day receiving information through technologies, and about $24 \%$ of this time is spent on computer activities such as browsing the Internet, playing video games, writing messages and watching videos. The average time users now spend on the Internet is 6 hours and 42 minutes, and that applies worldwide (Hootsuite $\&$ We Are Social, 2019). Most of that time is spent on entertainment activities delivered to users by visual or auditory means. According to the latest GlobalWebIndex survey (Hootsuite \& We Are Social, 2019), 93\% of all Internet users watch online videos, $70 \%$ use music streaming services, $51 \%$ watch vlogs, $47 \%$ listen to online radio broadcasting and 39\% listen to podcasts. None of these popular Internet activities involve the written language in any significant way.

However, the question we will focus on in this study is specific. The more general objective of this article is to examine aspects of the transition from printed text to digital form that are changing the nature of reading itself, and which have the potential, at both individual and collective levels, to lead to a paradigmatic change in pedagogy. From the wide range of topics relevant to this area, we have chosen to focus on the status of alphabetic text in digital, screen-based texts, and look at the implications for access to knowledge this change entails. We are interested in how the changes brought about by the digital era affect how and by what means individuals read and how they are changing people's (cognitive) abilities. We are also interested in the dynamics of this relationship, and what this trend - the retreat of the written language at the expense of other modalities for mediating meaning - means in terms of stimulating or suppressing the development of specific mental abilities acquired through the use of written language alone. We start from the fact that the spread of general education and literacy is tied up with 
the invention of the alphabetic script and has shaped our civilization. The change in the nature of reading in the digital era therefore affects the most important cultural invention of our civilization - literacy - and people's attitude to knowledge, leading to the idea of accessible education for all (Havelock, 1982).

In this study, we aim to identify and analyse the differences brought about by the newly emergent text architecture and the replacement of alphabetic, printed text with screen-based text, and ask whether this new ontological variant could bring about a change in the epistemological "quality" of reading. We also focus on the essence of these reading features and how they differentiate the reading path chosen.

\section{Change in Text Architecture Prompting a Change in Reading}

The emergence of a new reading and learning paradigm

Our everyday experiences and the growing empirical research indicate that reading has changed. In general, there has been no decline in the marketability of books, the symbol of traditional literacy (Baricco, 2006). However, there has been a decline in reading as a cultural activity. The act of continuous reading stimulates the capacity for realization, insight, and discovery, supporting deep reading (Wolf, 2016). But it is being pushed aside by a new reading style "that is able to integrate multiple sources of information, but that often appears fragmented, less focused, and potentially less able to attain previously achieved depths of concentration, comprehensiveness, and even immersion in reading" (p. 5). Baron (2015) refers to this as reading on the prowl, which involves skimming texts and scanning for information among other things.

This comes as no surprise. Decades ago the first theories on the impact digital technologies have on reading began to appear. First television, and later computers, were criticized in relation to reading and learning. One of the main thinkers writing about the end of alphabetic text (or linear code), the Czech philosopher Vilém Flusser, has put forward many arguments favouring a return to the era of images, based on a new technical coding that differs from the linear coding characteristic of alphabetic text (2012). Flusser argues that as technologies produce different coding (cameras, computers, pixels) the way we read will change and contribute to the breakdown of "collective memory". The media theorist and philosopher Marshall McLuhan 
had a similar idea: in his historical scheme of the development of human communication, he anticipated the decline of the book era and the onset of the technological era. Similarly, philosopher and journalist Neil Postman (1986, 1995) pointed out that new technologies were leading to individuals becoming gradually isolated in learning. Many other authors like Jean Gebser, Ken Wilber and Hugo Enomiya Lassalle have had similar ideas.

Some analytical popular writing has shown that the decreasing level of general knowledge of the population and the superficiality of young people's text comprehension is related to changes in leisure time and contact with others through digital media (Carr, 2010; Bauerlein, 2008; Spitzer 2012). Their conclusions add to research findings by neuroscientists, literature scholars and educators indicating that the use of digital technologies, specifically reading in digital form, affects neuron levels and changes the architecture of mental functions, especially in young people (Baron, 2015; Greenfield 2015; Wolf 2016).

In many works, the use of digital technologies to display educational texts (for example the digitization of educational content) is seen as both pragmatic and essential in the information era, and focus on describing the changes in form and the implications for reading (Alexander \& DRLRL, 2012). However, the problem of on-screen text in mediating information and providing a source of knowledge in education goes deeper and reveals the role of written speech as an intellectual tool for the development and mental organization of language use and for the formation of specific human capacities and strengths, compared to cultures that do not have this intellectual tool (e.g. Cole \& Cole 2006; Brockmeier \& Olson, 2009).

\section{A new platform for text ontology}

If we view written language as an intellectual tool, as a specific cognitive function operating via the techniques of administration and regulation, that creates the ground for justifying (Goody, 1987) changes in the transition from traditional, paper-paper based text to screen-based text of both an ontological and paradigmatic nature (Husset, 2006). The main component of traditional, paper-based text is alphabetic text, while screen-based text contains other components, especially visual ones, and this has profound implications for understanding text.

Ontologically, the form of texts is being transformed. Texts that use digital technologies rely only partially on alphabetic text to communicate meaning 
and make the information available through other modalities of meaning. Changes are also occurring in the way meaning is constructed in different contexts (e.g. Jeník, 2010) and reading "practices" in the digital era, and therefore it is possible to record paradigmatic changes as well. The transfer of learning processes and materials to digital form, or the replacement of more traditional, paper-based texts with screen-based texts, thus not only changes the medium and the manner in which teaching content is displayed, but the nature of literacy as well and the activities that promote and enable it.

More specifically, digitization changes the type of media, requiring a different kind of control and a different type of interaction than paper-based mediums such as books (Mangen, 2017). But it also bring about a change in text modality, in the way blocks of text are arranged on the digital media page (Waller, 2012). The specific visual experience of a digital text also affects the way it is read - understood (a psychological and semiotic problem), "detection" of meaning, which may not reflect the preferred meaning. Many philosophical theorists have pointed out these semiotic and hermeneutic connections (R. Barthes, M. Foucault, D. Davidson, Goodman and others). They have also discussed the way individuals perceive the reality of what is displayed (a phenomenological and epistemological problem) using the new text architecture and understand it (Jeník, 2012). Here, we are referring to ways and forms of representation that convey the meaning to us.

\section{Multimodality related to text architecture}

The focus of this paper is text that incorporates digital visuals. We will analyse this (comparing to paper-based text) on the basis of textual modality. But first we must clarify the nature of this textual characteristic, often thought to be distinctive.

The problem is that all communication is inherently multimodal, whether it is spoken communication or text-based communication, including digital forms of representation. Spoken communication contains multimodality, for example the linguistic code associated with rhetorical emphasis, pauses, and voice muting (Kress, 2005). In more traditional textual formats, (alphabetic text) multimodality manifests itself in specific ways of communicating meaning. In addition to illustrations, other static visual elements contribute to multimodality, such as different font sizes, their shape and thickness, design and location (Tolva, 1996). How the space on the page is used, the layout of the text and illustrations, the font size, line structure, and blank 
spaces create dynamics and rhetoric of expression and contribute to the cohesion of the formal rendering of text elements and communicated meaning (Bearne, 2009).

Multimodality is therefore typically found in the traditional repertoire of text media as well. Text genres such as newspapers, magazines, cookbooks, dictionaries, encyclopaedias, atlases, lists, and so on (Goody, 1977), utilize the representational capacity of static visual elements (including the way blocks of text are organized on a page) to extend the repertoire of meaning, its representational capabilities and to allow different readers find their own reading paths (Prior, 2005). A good example is the way in which the selection of a particular font can help communicate a specific meaning. The use of Imperial Roman fonts by classical Italian humanists, for example, emphasized their roots in ancient tradition, and their efforts to return the forgotten heritage of the ancient world to the European cultural space. By contrast the widely used Blackletter font was supposed to draw attention to itself (Wysocki, 2004). The way a word is written on the page of a book can express a richer variety of meanings than the word itself, simply by "suggesting" how the word should be read and what emotion should be identified behind it (Hasset, 2006). Even in this context, contrasts between the alphabetic text and the visual elements (highlighting the author's ironic tone, for example) cause no problem because they coexist side by side as text elements and help to communicate the meaning, by making reference to the alphabetic text. For example, in his philosophical semiotics, Foucault (2008) considers a drawing by Magritte drawing in which the title communicates something quite different from the drawing, forcing the reader to analyse more deeply the meaning denoted.

However, there is some predictability and synergy between alphabetic text and other elements of text genres. The way the text is typically arranged in a dictionary, encyclopaedia or newspaper allows the reader to recognize the genre and should prompt an appropriate reading path. The synergy between alphabetic text and other static visual elements comes from the fact that the elements of the other modalities support the meaning of the alphabetic text. For example, the relationship between an image and an alphabetic text can have an important illustrative and persuasive function. If the alphabetic text is linked to other static visual elements in paper-based text, greater attention is drawn to the alphabetic text. This is evident in children who are still at the pre-reading stage following the illustrations of the story to gain access to the meaning of the text they are not yet able to fully decode. 


\section{Multimodality of non-linear digital reading}

However, the synergy between the alphabetic text and other visual elements may not always work well in on-screen texts. Digital text is arranged as a text of discontinuous meaning, making it possible to perceive different text forms (often of different modalities) as closed semantic units, in other words, as blocks of texts and in a loose format that is navigated in a nonsequential, non-linear way. Thus, the reader does not access the text as mediating continuous meaning (in sequential, linear form), but as specific blocks of text of variable structure that can be displayed on the digital media screen in different ways, depending on which one and in what order the reader chooses to focus on them (or open them if in hypertext) (Landow, 1994). Screen-based text lacks a clear chronology, which would in other situations impair understanding and make it impossible for the reader to continue. But in screen-based text the reader is able to skip parts (even when not authorized to do so) and arrive at generalizations that may be logically inconsistent.

When reading screen-based text, we navigate and process the page layout, illustrations, typeface, and typography (Walker et al., 2018). We can use these digital text design indicators to explore and identify how the changing text design and media transform the visual experience of reading and affect its processual features. There are pedagogical and didactic implications, because they change the way students approach the elements present in educational texts and how they benefit from them when studying a particular issue. However, in this study we go beyond the design of screen-based text and ask how text design modifications (including blocks of text of different modalities) affect the role of the written, alphabetic text in constructing meaning. Writing developed as an intellectual (cultural) tool, which uniquely, and through the change in the text architecture reflected in the architecture of the human mind, contributed to the formation of textual minds (van der Weel, 2011), which have influenced the development of formal school education (and the school itself).

\section{Visual Experience of the Text and Access to Meaning}

Access to meaning in the "era of linearity"

With the invention of the written language and its dissemination through the printing press, "print culture" was established. The written culture was 
consolidated through written language genres, the authorship of texts, and books becoming the symbolic representation of the intellectual values of higher culture and the emergence of the concept of the reader (Hesse, 1996). In addition to the "print culture", terms such as "Gutenberg Galaxy" (McLuhan 2005, p. 35) or "Linearity Era" (Flusser 2011, p. 20) are used when talking about this period. All these terms denote the period in which linear, paper-based reading prevailed. The typical reading path in this era consists of the gradual, continuous reading of the alphabetic text of a book from first page to last page.

In this tradition, books and printed text enabled cultural production and reproduction, as they recorded the author's thoughts in a formally organized form (corresponding to the functional aspects of the written language and the corresponding text genre), cognitively representing the beginning and end of the author's reasoning. This linear text was a means whereby the author's ideas could reach a large number of readers who were then able, by decoding the linguistic features, to interpret it in an unlimited number of contexts and critically reflect upon them. The emergence of critical reflection in ancient times led to the transition from uncritical, mythical thinking to logos, or rational reasoning (Ong, 2002).

Some have criticized this monopolization of attention on the alphabetic text for suppressing our natural senses. Lanham (2001) therefore welcomes the development of textual designs that create the illusion of three-dimensional space (through the use of graphic techniques). Textual expression which uses a sophisticated visual text design and expands multimodality does not therefore have to rely solely on alphabetic text that acts as an "objective correlate" to express the spoken word and that is gradually losing its visual content and the power to encourage thinking (Lanham, 2001). The use of textual design to create the illusion of three-dimensional space thus enables the reader to go beyond a perception of the world that is based on the limited expressive form of the linear text. This is to be contrasted with situations in which visual perception is a spatial ("stereo" event taking place in a three-dimensional world) experienced through the long-term use of script as a communication medium.

In the era of linear code, the image was particularly dominant in children's books. However, thanks to digital texts, the image is increasingly found in texts for readers with advanced reading skills. To the detriment of alphabetic text, in digital text pictorial texts are displayed in numerous representations and overshadow the alphabetic text (Jewitt, 2005). Therefore, 
when discussing the changes brought about by the transition to digital text, we ned to analyse the representational potential of the alphabetic text and image.

\section{Accessing meaning through scriptorial and pictorial signs}

The analysis of the representational potential of alphabetic text and image can be approached on several levels. In this section we will discuss the relationship between the form of external representation (sign) and the interpretation of its meaning, looking at how the different visual experiences of the alphabetic text and image affects the way individuals construct the meaning of the text and perceives the reality displayed through the alphabetic text and image.

The meaning of a sign is interpreted by interconnecting semiotic and psychological aspects. Meaning cannot be decoded without the individual who creates that relationship as it requires establishing the relationship between the sign and its mental or cognitive inner representation. Both scriptorial signs and pictorial signs (pictures) appear to be intentional signs that were created by someone to evoke meaning in those encountering them. Although, we can distinguish the representative potential of word and image in dimensions such as motivated versus arbitrary, personal versus conventional origin and isolated versus systematic, the difference between them will be shown in the dimension of isolation versus systematicity (Tolchinsky, 2003). Scriptorial devices are part of a system (alphabetical written language) and the meaning of each element in that system is determined by the system itself. By knowing which element belongs to the system and its position in the system, we can use these elements in different contexts and express different content and meaning. This characteristic of scriptorial features enables us to identify sequences of features with some degree of clarity, since we can clearly identify the features and the rules of arrangement, even if we interpret them differently. When identifying the various elements in an image, we do not have access to this unique system. Despite there being ample opportunity for interpretation, the meaning of the image is unclear and fragmentary (Fišerová, 2015b).

In any case, both pictorial and scriptorial signs have to be viewed in terms of their potency as tools of communication and cognition. They expand or change our mental abilities and allow us to adopt different perspectives on reality, and so are the drivers of multiple cognitive operations generating cognitive change, both in terms of quantity and cognitive flexibility (Tol- 
chinsky, 2003). The special cognitive potential for interpreting scriptorial signs as communication and as cognitive tools seems to lie in reading "the mind's traffic in signs and signifiers," in "the most dynamic, changeful, and possibly transformational act we can imagine" (Birkerts, 2007).

However, to better understand the potentialities of scriptorial and pictorial signs as communication and cognitive tools, we have to go beyond the level of simply decoding the meaning of a particular sign and examine the conventions of written language. Because, while there is great degree of flexibility in the way pictorial features (image) can be arranged on the surface, written texts have to follow a particular directional orientation that results in consistency in text presentation, affirming the dominance of the author. This is achieved through page numbering, chapters that cannot be read in random order and location on the page. Readers then use these to navigate their way through the text, beginning on the left-hand page and reading from left to right, top to bottom and then continuing onto the right-hand page. The reading order is determined by the concept of print and the linguistic means (lexical, grammatical) of expression.

The written conventions and textual consistencies and the standard nature of composition draw readers' attention to the text. This is a crucial characteristic of reading, giving access to meaning. Readers are guided by the way the text is arranged and can therefore attribute meaning to the words, using their knowledge and ability to analyse, predict, ask questions and formulate assumptions. Readers therefore actively approach meaning as the act of constructing meaning - of interpreting and that establishes the openness of the text (Eco, 1962).

Alphabetic text is arranged in a linear form that implies a certain logic of its available functions, unfolding in a particular time sequence (Kress, 2005). Alphabetical text, with its predetermined arrangement, reveals its individual elements, unit by unit, to its readers who then come to gradually understand the meaning of the text as a whole. Kress (2005) argues that this gives the author some power over the reader, who is dependent on these elements of the text being gradually revealed to him or her. However, no matter how precisely the author uses the available language resources or tries to openly direct the reader, readers respond individually to the text. Reading is the result of the imagination of the reader, which goes beyond the interpretative possibilities of the text set by the author (Birkerts, 2007).

Images seem obvious to us in terms of their content. We recognize the individual elements, but we are not exactly sure what we know because we 
lack the means to communicate what we "read" when we perceive the image (Kress \& van Leeuwen, 1996). Therefore, according to Flusser (1993), images may indicate more than they designate. While designation has a clearer course, and meaning is a matter of sign function (the term denotes an idea), images merely indicate or specify an idea whose discovery may not be related to meaning. Images - surfaces with meaning - are two-dimensional and replete with meaning, while texts are open to meaning and contain and require in-depth analysis.

When navigating the elements of the image in an attempt to perceive or decode them, we must adopt a different approach with pictures. Although the elements of a picture are arranged in a particular way in space and are available to us the recipients, we have to arrange them into sequences that make sense to us according to our interest. Our imagination therefore focuses on creating organizational order out of the elements of the image that have the meaning expressed by the author (Kress, 2003).

\section{Analytics and the abstract nature of reading an alphabetic text}

The era of linearity, associated with the use of the alphabetic code, allowed humankind to reach more abstract levels of knowledge and go deeper and greater concentration into the meaning of the text. As a consequence, this kind of text contains more abstract terms and a larger vocabulary. It may employ depersonalized (and thus more decontextualized) language and be more explicit, elaborate (syntax) and formal (Goody, 1987). Studies analysing the implications of using written language as an intellectual tool in the field of human consciousness show that written language has an important function in the individual's development, but also in shaping the structure of society, that is related to the liberation of intellect. Concepts such as the "literary mind" (Turner, 1996) or the "textual mind" (van der Weel, 2011) are the outcome of research that has identified written language as a powerful cultural tool that changes the rational organization of our experience and our relationship with it. With this kind of reading, critical thinking is born, leaving behind the magical moments of humankind and mythical truths. The fact that we can return to a particular idea when reading or writing a text encourages us to analyse and adopt a more objective stance on the written text (Ong, 2002).

It is not only the nature of the written language that is important. The fact that it is received in the form of a linear code through visual means concentrates our attention on the different elements that make up the parts 
of the sentences, which readers perceive gradually as the relations between them are formally revealed, set by the author or through writing conventions (syntax, reading direction, the placing of the word on the page, in the text). This, as Kress (2005) explains, entails an epistemological commitment, which results from the identified type of relationship between the individual elements of the alphabetic text, through the arrangement of the linguistic means. The elements of the alphabetic text are not left for the reader to encounter but are gradually revealed with reference to their mutual relations. For example, in the sentence "John throws a stone", the epistemological commitment is expressed in the relationship between "John" and "stone" as "throwing", where the activity is performed by "John" and focuses on the "stone". The relationship between the different elements of the text, "John", "stone" and "throwing", are not arbitrarily determined by readers; they are guided by the conventions of the written script through the linear code and their knowledge of grammar.

The relationship between the elements of a text therefore differs from that between the elements of an image. The latter is predominantly constructed by the recipient because the form of representation does not allow them to be determined. Therefore, while we work with the epistemological category of knowledge when reading an alphabetic text, when interpreting an image, we rely on the information that can be represented in this mode. We look at the image and preview (Einsicht) it, which brings us to a "space with meaning" (Flusser) but also gives us an initial view (Ansicht). Digital images (photography, e-books, hypertexts) have additional characteristics (we will look at this more in the next section). If we look at a digital image that offers us a more diverse structure and more selectable reading methods than the classical linearity of an alphabetic text, we realize that it does not go deeper than the information and does not allow us to look into deeper connections. Digital images are "more exciting" and stimulating, which can detract readers from the original storyline or line of reading. Let's take a closer look at these characteristics.

\section{Digital Text Design and Accessing Meaning}

With the digital revolution, the architecture of texts is changing. Their multimodality, the combination of visual, audio and alphabetic elements of text, draws the reader into a page design that, in the way it is used (approach to meaning), takes text reading away from the linear organization of elements revealed in time-ordered sequences and back to space (Lanham, 2001). This broadens the potential interpretative repertoire of the 
text's meaning and weakens the status of the alphabetic text. As Lanham (1993) explains, the reinforcement of the multimodality of the text creates space for the reader's perceptual field to broaden, which, given the nature of human sensory abilities, should reunite visual intelligence with abstract thinking, which are separated in script and print. However, Miall and Dobson (2001) counter that this is not reflected in the empirical evidence. In fact, the presence of pictorial elements tends to evoke subliminal feelings and affects perception of the text without the reader having to consciously evaluate their meaning, that is, to critically analyse and reflect. A good example is advertising, which clearly taps into the most sensitive and receptive points of the human psyche. The reactivity to the icons (i.e., semiotic images) directly corresponds to their scope and helps the consumer to positively identifywith this icon.

This is also true of literary reading. If readers only have an alphabetic text, the text is received in terms of ability to create a fictional world from the symbolic language-based representation (Mangen, 2008), which is constructive and personal. The understanding readers obtain when reading an alphabetical text comes from the knowledge, beliefs and values that have a personal impact on them. When reading a text, individuals may not always be fully aware of how they create their own imaginations, yet experience reading the text as a personal event allowing them to engage with it and experience in-depth text reading (Wolf, 2016). Adding elements of other modalities to screen-based text (for example, illustrations, videos, signature tunes, banners) limits the range of available meanings and decreases the potential for personal reactions to and deeper reflection or immersion in the text (Mangen, 2008).

\section{Broader context of reading screen-based texts}

The availability of digital images has fundamentally transformed the way today's generation read. The great boom in digital media has led to the abstract thinking abilities available in deep reading being substituted by skimming, a process in which the subtle hues and hermeneutical circle of questions and answers are ignored in the search for explicit meaning. For today's generation, instant information, both in terms of presentation and expression, takes precedence over deep, analytical thinking (Baron, 2015).

When text is presented on a screen, the digital format simplifies and reduces the information, and the semantic richness of the content is no longer important. It is here that the phenomenon of image plays a very important 
role; it is sufficiently "magical" to convey fascination (originally conveyed by texts as well), but at the same time it can convey it in a much easier way - without the need for a conceptual scheme. Imago provides opportunity for greater and better imaginations, which the young generation is surely bursting with. The typology of the text has been replaced by the typology of the picture, known as "icons" in semiotics (C. Peirce), symbolic images with meaning. Pictures provide enough incentives to saturate the intensity but do not allow definite signification in terms of meaning. In addition, the image can be "ambiguous" when compared to text, not indicating anything in particular.

An important aspect of digital reading - it would seem - is "experiential", "superficial" reading. Multimodality allows for greater variability, imaginativeness and a more sensual "fulfilment" of reading. While printed books offers us minimum incentives - just the stimulus of "simple impression" or the logical thread of the text - digital books enable a greater variety of modalities of reading and have a more colourful, attractive architecture. With linear text we can become more immersed in the text and focus on the content and "objective" information. Whereas digital text - image and script combined has no clear definition.

Images that become part of the script in screen-based text simulate both and at the expense of both. Digital texts offer possible reading variations that show more creativity and proffer more interpretations, but they are not linear texts in the true sense of the word. Flusser calls them "surfaces" (Oberfläche). An image is a surface, a two-dimensional surface, with an indefinite meaning. The meaning is often understood once the idea has been identified, but that is a more complicated task than reading a text. On one hand, the combination of image and alphabetic text simulates the linearity of text, but at the same time the text is presented in a colourful and multistylized form that has no clear logic of expression. The symbolization of the image makes the deconstruction of meaning more difficult, resulting in a greater, creative sense in reading, and young people today are better able to identify the causal symbolism of partial semiotics and have better imaginations. However, it also hampers the ability to study broadly and deeply, concentrate on ambiguous texts for long period, stratify text architecture or logically analyse and find one's way around a text. The following summary of what the reading of digital texts inhibits, "reading longer texts, rereading, deep reading, memory of what was read, individual (rather than primarily social) encounters with books, stumble-upon possibilities, strong emotional involvement" (Baron, 2015, p. 213), raises the question of whether individu- 
als really benefit from the potential offered by the multimodal textual design of digital texts.

\section{Comprehension-related processes and reading screen-based texts}

On one hand, readers working with digital texts have access to text elements of various modalities that can be read in the order of their choosing. They have multiple entry points, reading paths and exit points, and the knowledge obtained corresponds to readers' needs, preferences and knowledge. However, empirical research shows that the nature of reading is changing, and reader profiles (written language user) suggest these new opportunities are not being sufficiently exploited by readers to improve comprehension-related processes, or at least not convincingly (Delgado, Vargas, Ackerman \& Salmeron, 2018). Readers have difficulty constructing meaning when it is presented using various modalities and is non-sequentially arranged on the page ("sound bites", "thoughts bites"), as is typically the case with screen-based texts. This is because they have to handle the meanings presented in the alphabetic text as well as in the image (or sound) and integrate meanings presented through different modalities. The design of digital texts therefore makes it easy for the reader to become distracted. As reading experts have noted, the processes most affected from the procedural point of view are those associated with deep reading - inferential and deductive reasoning, analogical skills, critical analyses, reflection and insight (Wolf $\&$ Barzillai, 2009).

This is confirmed by a meta-analysis on the effects of reading media on reading comprehension conducted by Delgado et al. (2018). They analysed 54 empirical studies, comparing the reading of comparable texts, print materials and on-screen texts published between 2000 and 2017. Their results show that respondents reading a digital text understood less, regardless of the research methodology and theoretical framework, and this has been confirmed by other research findings (Kong, Seo \& Zhai, 2018; Singer \& Alexander, 2017; Wang, Jiao, Young, Brooks \& Olson, 2007). They concluded that the digital environment is not always appropriate for fostering deep comprehension and learning, and that "providing students with printed texts despite the appeal of computerized study environments might be an effective direction for improving comprehension outcomes" (Delgado et al., p. 34).

The digital environment does not suppress reading, it merely changes the appearance of the text, focusing more on "media design", and on a visual ap- 
proach to meaning than on providing opportunities for concentrated reading, using alphabetic text above all. The type of reading that stimulates the acquisition of "cognitive patience" (Wolf, 2016), needed when reading more dense, demanding texts from any sphere closely related to education, is gradually disappearing. There is justified concern that the increasing use of digital reading will lead to "second orality" (Ong, 2002), in which the qualities of the human intellect that stimulated the transformation of visual and auditory perception, cognition and linguistic functions through the use of written speech are being lost.

\section{Further incentives and implications for next generation education and literacy}

The use of the image, investigated in previous studies in relation to teaching and learning opportunities in schools in the digital era, points to a paradigmatic change in educational approaches. The introduction of new digital media in schools, the transfer of some learning processes to the screen or online environment along with the creation of digital education platforms often prompts optimistic visions of better access to education and literacy, especially for vulnerable groups of individuals (Wolf, 2016), and analyses of the changes the transformation brings. The discussion in the field of reading and in response to the arrival of the digital era concerns the nature of the "new literacies", "multiliteracies" and "literacy for the 21 st century" (Mills, 2010) and how readers have to be capable of understanding the code used when alphabetic text carries only part of the meaning. Kress and van Leeuwen (1996) recommend revisiting the way modes of representation are dealt with in the school curriculum and moving away from the preference for alphabetic text so various forms of representation can be included. This would require us to reduce the strong emphasis on the visual mode (image and text design) as the basis for a new kind of reading as it is insufficient, and explain how the status of print, reader and learner, and the role of the classroom teacher will change.

A number of studies show how the learning individual, digital media and teachers all interact, and point to the new kinds of reading, writing and play that emerge through contact with new media. They also indicate how meaning-making works in the multimodal environment of screen-based text, both in relation to reading and creating meaning. There is a relatively comprehensive summary on the situation regarding early childhood in The Emerging Field of Digital Literacies in Early Childhood edited by Erstad, Flewitt, Kümmerling-Meibauer and Pereira (2019). While Learning to Read in a Digital World (Barzillai, Thompson, Schroeder \& van den Broek, 2018) has 
a more general focus on reading. Other review studies mapping the changes in reading texts on screen show that the research on the multimodality of digital text or hybrid semiotic systems provides a fairly comprehensive picture of what forms of text design are available in the digital environment and how individuals read and learn in that environment (Jewitt, 2008), and include practical demonstrations and recommendations for educational practice (Walsh, 2010).

On the other hand, there are studies of on-screen reading that not only identify changes in the semiotic landscape of textual resources in the digital era but also set out an integrative conceptual and theoretical framework for investigating reading. When we focus on reading as a human-technology interaction and as an embodied act, we reveal the key dimensions of reading: ergonomic, attentional/perceptual, cognitive, emotional, phenomenological, socio-cultural and cultural-evolutionary (Mangen \& van der Weel, 2016). Mangen and van der Weel (2016) have suggested we formulate research questions that reveal the effects of digitization on reading across these dimensions. Such an approach would support our understanding of "what reading is fundamentally, how it actually works as a process and which human faculties are involved" and "it should help explain better the effect of reading on the individual brain" (p. 121). In addition to understanding the reading process itself, whether on paper or on screen, this approach to investigating reading would make it possible to identify which kinds of abilities reading helps to develop and what we should seek to preserve in teaching reading and literacy development. Otherwise, the "new literacies" or "multiliteracies" era may be gradually replaced by the "post-literacy" era (Ong, 2002), and the specific functions brought into the architecture of our mind by written language would disappear. If written language and the related forms of access to knowledge are no longer a priority in the plurality of semiotic sources and individual forms of cognition, where will schools derive their legitimacy from? This question requires more detailed analysis examining the specificities of the use of digital texts in schools.

\section{Acknowledgements}

This paper is based on work supported by a grant from the Slovak Ministry of Education, VEGA 2/0134/18 Pedagogical impacts and developmental achievements resulting from curricular changes in preschool education and APVV-15-0189 Selected factors of a pro-family strategy and stable families in a multicultural environment. 


\section{References}

Alexander, P. A., \& The Disciplined Reading and Learning Research Laboratory. (2012). Reading into the future: Competence for the 21st century. Educational Psychologist, 47(4), 259-280.

Baricco, A. (2006). I Barbari. Saggio della mutazione. Rome: Fandango libri.

Baron, N. (2015). Words onscreen. The fate of reading in a digital world. Oxford: Oxford University Press.

Barzillai, M., Thompson, J., Schroeder, S., \& van den Broek, P. (Eds.). (2018) Learning to read in a digital world. Amsterdam / Philadelphia: John Benjamins Publishing Company.

Bauerlein, M. (2008). The dumbest generation: How the digital age stupefies young americans and jeopardizes our future. New Yourk: Jeremy P. Tarcher/Penguin.

Bearne, E. (2009). Multimodality, literacy and texts: Developing a discourse. Journal of Early Childhood Literacy, 9(2), 156-187.

Birkets, S. (2007). Reading life. Books for the ages. Minnesota: Graywolf Press.

Bohn, R. E., \& Short, J. E. (2009). How much information? 2009 report on American consumers. Global Information Industry Center: UC San Diego, CA. Retrieved from http://hmi.ucsd.edu/howmuchinfo.php

Brockmeier, J., \& Olson, D. R. (2009). The literacy episteme: From Innis to Derrida. In D. R. Olson, \& N. Torrance (Eds.), The Cambridge Handbook of Literacy (pp. 3-21). Cambridge: Cambridge University Press.

Carr, N. (2010). Shallows. What the internet is doing to our brains. New York: W. W. Norton \& Company.

Cole, M., \& Cole, J. (2006). Rethinking the goody myth. In D. Olson, \& J. Cole (Eds.), Technology, literacy, and the evolution of society. Implications of the work of Jack Goody (pp. 305-324). Mahwah, New Jersey, London: Lawrence Erlbaum Associates. Delgado, P., Vargas, C., Ackerman, R., \& Salmerón, L. (2018). Don't throw away your printed books: A meta-analysis on the effects of reading media on reading comprehension. Educational Research Review, 25, 23-38.

Eco, U. (1962). Opera Aperta: forma e indetermninazione nelle poetiche contemporare. Milan: Bompiani.

Erstad, O., Flewitt, R.S., Kümmerling-Meibauer, B. \& Pereira, Í S. P. (Eds). (2019). The Routledge handbook of digital literacies in early childhood. London: Routledge.

Fišerová, M. (2015a). Kybernetické imaginárno. Rozhovor s Pierrem Lévym. In M. Fišerová (Ed.), Obraz a moc. Rozhovory s francouzskými mysliteli (pp. 134-140). Praha: Karolinum.

Fišerová, M. (2015b). Politika obrazu ve francouzském myšlení 20. a 21. století. In M. Fišerová (Ed.), Obraz a moc. Rozhovory s francouzskými mysliteli (pp. 10-84). Praha: Karolinum.

Flusser, V. (1993). Lob der Oberflächlichkeit. In S. Bollman, \& E. Flusser (Eds.), Schriften (volume 1) (pp. 9-59). Düsseldorf: Bollman Verlag.

Flusser, V. (2011). Does writing have a future? Minneapolis, London: University of Minnesota Press.

Foucault, M. (2008). This is not a pipe. Los Angeles: University of California. 
Goody, J. (1977). The domestication of the savage mind. Cambridge, UK: Cambridge University Press.

Goody, J. (1987). The interface between the written and the oral. Cambridge, UK: Cambridge University Press.

Greenfield, S. (2015). Mind change: How digital technologies are leaving their mark on our brains. New York: Random House.

Harari, Y. N. (2016). Homo Deus. A brief history of tomorrow. New York: Random House.

Hassett, D. D. (2006). Signs of the times: the governance of alphabetic print over "appropriate" and "natural" reading development. Journal of Early Childhood Literacy, 61(1), 77-103.

Havelock, E. (1982). The literate revolution in Greece and its cultural consequences. Princeton, NJ: Princeton University Press.

Hesse, C. (1996). Books in time. In G. Numberg (Ed.), The Future of the Book (pp. 2133). Berkley, Los Angeles: University of California Press.

Hootsuite, \& We Are Social (2019). Digital 2019 global digital overview. Retrieved from https://datareportal.com/reports/digital-2019-global-digital-overview.

Jeník, L. (2010). Svet filozofického románu ako laboratórium filozofie. Romboid, 45(3), 24-37.

Jeník, L. (2012). Náčrt Goodmanovho chápania úlohy metafory v jeho teórii referencie. Studia Aloisiana, 3(2), 17-36.

Jewitt, C. (2005) Multimodality, "reading", and "writing" for the 21st Century. Discourse: Studies in the Cultural Politics of Education, 26(3), 315-331.

Jewitt, C. (2008). Multimodality and literacy in school classrooms. Review of Research in Education, 32(1), 241-267.

Kong, Y., Seo, Y. S., \& Zhai, L. (2018). Comparison of reading performance on screen and on paper: A meta-analysis. Computers \& Education, 123, 138-149.

Kress, G., \& Van Leeuven, T. (1996). Reading images: The grammar of visual design. London: Routledge.

Kress, G. (2003). Literacy in the new media age. London: Routledge.

Kress, G. (2005). Gains and losses: New forms of texts, knowledge, and learning. Computers and Composition, 22(1), 5-22.

Landow, G. P. (1994). Hyper/text/theory. Baltimore: The Johns Hopkins University Press.

Lanham, R. A. (1993). The electronic word: Democracy, technology and the arts. Chicago: Chicago University Press.

Lanham, R. A. (2001). What's next for text? Education Communication and Information, 1(1), 15-36.

Mangen, A. (2008). Hypertext fiction reading: Haptics and immersion. Journal of Research in Reading, 31(4), 404-419.

Mangen, A., \& van der Weel, A. (2016). The evolution of reading in the age of digitisation: An integrative framework for reading research. Literacy, 50(3), 116-124.

Mangen, A., (2017). Textual reading on paper and screens: Implications for design. In A. Black, P. Luna, O. Lund, \& S. Walker (Eds.), Information design research and practice (pp. 275- 290). London: Routledge. 
McLuhan, M. (2005). Understanding Media. Abingdon: Routledge.

Miall, D. S., \& Dobson. T. (2001). Reading hypertext and the experience of literature. Journal of Digital Information, 2(1).

Mills, K. A. (2010). A review of the "Digital turn" in the new literacy studies. Review of Educational Research, 80(2), 246-271.

Ong, J. W. (2002). Orality and literacy. The technologizing of he word. London \& New York: Routledge.

Postman, N. (1986). Amusing ourselves to death. Public discourse in the age of show business. New York: Penguin Books.

Postman, N. (1995). The end of education. Redefining the value of the school. New York: Random House.

Prior, P. (2005). Moving multimodality beyond the binaries: A response to Gunther Kress' "Gains and losses". Computers and Composition, 22, 23-30.

Singer, L. M., \& Alexander, P. A. (2017). Reading on paper and digitally: What the past decades of empirical research reveal. Review of Educational Research, 87, 10071041.

Spitzer, M. (2012). Digitale Demenz. Wie wir uns und unsere Kinder um den Verstand bringen. München: Droemersche Verlagsanstalt.

Tolchinsky, L. (2003). The cradle of culture and what children know about writing and numbers before being taught. Mahwah, New Jersey, London: Lawrence Erlbaum Associates.

Tolva, J. (1996). Ut pictura hyperpoesis: Spatial form, visuality, and the digital word. In Proceedings of the seventh ACM conference on hypertext, Washinghton, DC, March $16-22$ (pp. 66-73). New York: ACM Press.

Turner, M. (1996). The literary mind. Oxford: Oxford University Press.

UNESCO (2015). Education 2030 Incheon Declaration - Framework for action for the implementation of sustainable development goal 4. Paris: UNESCO.

van der Weel, A. (2011). Changing our textual mind. Manchester, New York: Manchester University Press, 2011.

Walker, S., Black, A., Bassemans, A., Bormans, K., Renckens, M., \& Barratt, M. (2018). Designing digital texts for beginner readers: Performance, practice and process. In M. Barzillai, J. Thompson, S. Scroeder, \& van den Broek, P. (Eds.), Learning to read in a digital world (pp. 31-55). Amsterdam / Philadelphia: John Benjamins Publishing Company,

Waller, R. (2012). Graphic literacies for a digital age: The survival of layout. The Information Society: An International Journal, 28(4), 236-252.

Walsh, M. (2010). Multimodal literacy: What does it mean for classroom practice? Australian Journal of Language and Literacy, 33(3), 211-239.

Wang, S., Jiao, H., Young, M. J., Brooks, T., \& Olson, O. (2007). Comparability of computer-based and paper- and-pencil testing in $\mathrm{K}-12$ reading assessments: A meta-analysis of testing mode effects. Educational and Psychological Measurement, 68(3), 5-24.

Wolf, M. (2016). Tales of literacy for the 21st century. Oxford: Oxford University Press. Wolf, M., \& Barzillai, M. (2009). The importance of deep reading. Educational Leadership, 6, 32-37.

Wysocki, A. (2004). The multiple media of texts: How on screen and paper texts in- 
corporate words, images, and other media. In Ch. Bazerman, \& P. Prior (Eds.), What writing does and how it does it: An introduction to analyzing texts and textual practices (pp. 123-163). Mahwah, NJ: Lawrence Erlbaum.

\section{Authors:}

Zuzana Petrová, Assoc. Prof.

Tomas Bata University in Zlin

Faculty of Humanities

Department of School Education

Štefánikova 5670

76001 Zlín

Czech Republic

E-mail: zpetrova@utb.cz

Trnava University

Faculty of Education

Department of School Education

Priemyselná 4

91843 Trnava

Slovakia

E-mail: zuzana.petrova@truni.sk

Rastislav Nemec, Assoc. Prof.

Trnava University

Faculty of Theology

Department of Christian Philosophy

Kostolná 1

81499 Bratislava

Slovakia

E-mail: rastislav.nemec@truni.sk 